\title{
Polyester sponge swabs to facilitate examination for genital infection in women
}

\author{
J. K. OATES, S. SELWYN, AND M. R. BREACH
}

From the Venereal Diseases and Bacteriology Departments, Westminster Medical School, London, S.W.1

\section{The diagnostic problem}

Gonorrhoea in women is notoriously difficult to diagnose. Its non-specific, often minimal, features and the relatively inaccessible sites of infection cause problems for the clinician, and the delicacy of the pathogen, the occurrence of a rich commensal flora, and $\mathrm{pH}$ extremes create severe difficulties for the bacteriologist. Urethral, cervical, and if necessary, rectal specimens obtained by standard methods and examined by skilled laboratory staff may be expected to yield negative results at the first attendance in a third of infected female patients, and in as many as one case in ten diagnosis is not made until the third examination (Catterall, 1970). Recent attempts to improve diagnostic methods have been largely concerned with laboratory techniques: improved culture media (e.g. Seth, 1970), rapid fluorescent antibody staining (Thin, 1970), and serological tests (Norins, 1968). The most promising of these are the various immuno-fluorescence techniques, but these require specialized facilities and, although results may be obtained relatively quickly, they are not usually available at the first visit within an acceptable waiting period. Furthermore, they cannot replace conventional culture procedures because of the need for sensitivity testing and the identification of other potential pathogens. In the work to be described, an attempt was made to facilitate examination and diagnosis by the use of polyester sponge swabs for collecting specimens of genital secretions.

\footnotetext{
Disadvantages of current sampling methods A wire loop is generally used to collect specimens for microscopy, and material for culture is then taken either by means of a swab or by re-use of the loop. Frequently it is difficult to obtain adequate specimens of the tenacious cervical mucopus or of the generally scanty urethral discharge. The necessary scraping with the wire loop may be alarming for a nervous patient, and may be genuinely painful when urethral specimens are taken. This is especially so if the wire loop has not been carefully rounded when made, or meticulously examined when
}

Received for publication February 16, 1971 used, to ensure that there are no sharp edges or ends. In busy clinics the maintenance of loops in perfect condition $\infty$ is a difficult task, especially towards the end of a busy session when each group of loops will have been used, 윽 cleaned, and sterilized many times. In those clinics in which the wire loop is also used to inoculate culture media directly, two samples are required, and the same usually obtains when slides are prepared and media inoculated $\frac{1}{f}$ by means of cotton-wool swabs. An extra charcoal- $\overrightarrow{\vec{\theta}}$ coated swab is generally required if Stuart's transport medium is being used. Wool-tipped swabs are certainly $\rightarrow$ less uncomfortable for the patient, but the conventional swab picks up a relatively small and superficial sample of the genital secretion.

\section{The new swab}

We considered that better results might be achieved in diagnosis if a consistently larger and more complete sample of secretion could be collected from each site. More than one diagnostic slide as well as heavier inocula for culture would then be obtained from every specimen and there would be fewer manoeuvres during examination. For this purpose we prepared swabs from $35-\mathrm{mm}$. cubes of polyester sponge. ${ }^{1}$ Each cube was cut into strips measuring approximately $35 \times 5 \times 5 \mathrm{~mm}$. These were folded over the end of a wooden Macron swab stick, ${ }^{2}$ and spirally bound in position with about seven turns of $\frac{D}{O}$ cotton thread (Figure, overleaf). For collecting urethral specimens, a smaller size of swab was made $N$ using strips measuring $35 \times 3 \times 3 \mathrm{~mm}$. Two swabs of each size were then placed in rimless $150 \times 16 \mathrm{~mm}$. test tubes, closed with 'Cap O Test' reusable seals $\omega$ and autoclaved (10 lb./sq. in. for $20 \mathrm{~min}$.). With a? little practice, the clinic sister could prepare welle over 100 swabs an hour.

\section{METHOD OF USE}

Cervical specimens were taken by rolling the swab across $\mathbb{D}$ the cervix and when possible gently rotating it after

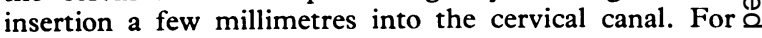

1. Campbell Brushes Ltd., Cranwell Street, Dudley.

2. McCarthy Ltd., North Street, Romford, Essex. 

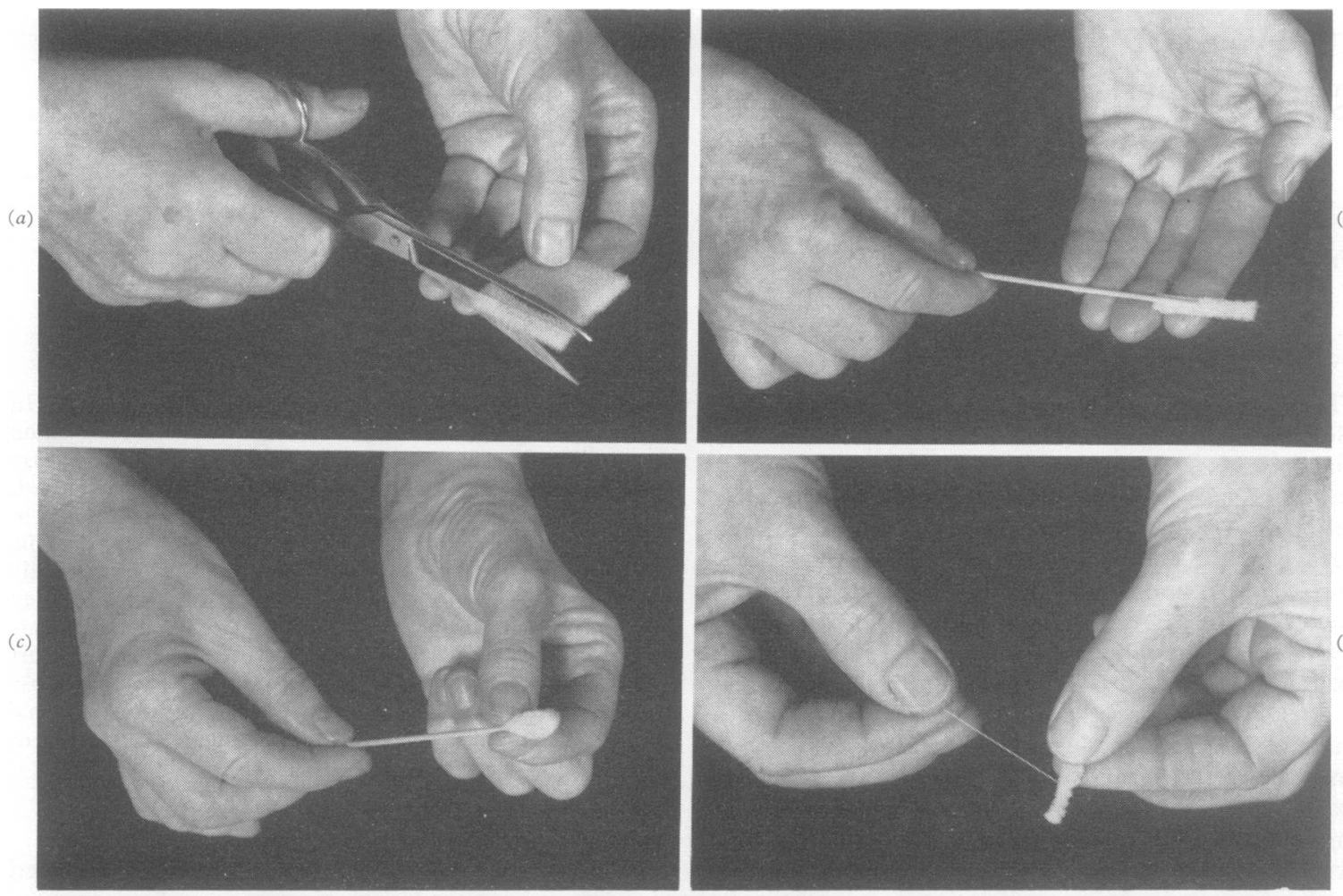

(e)

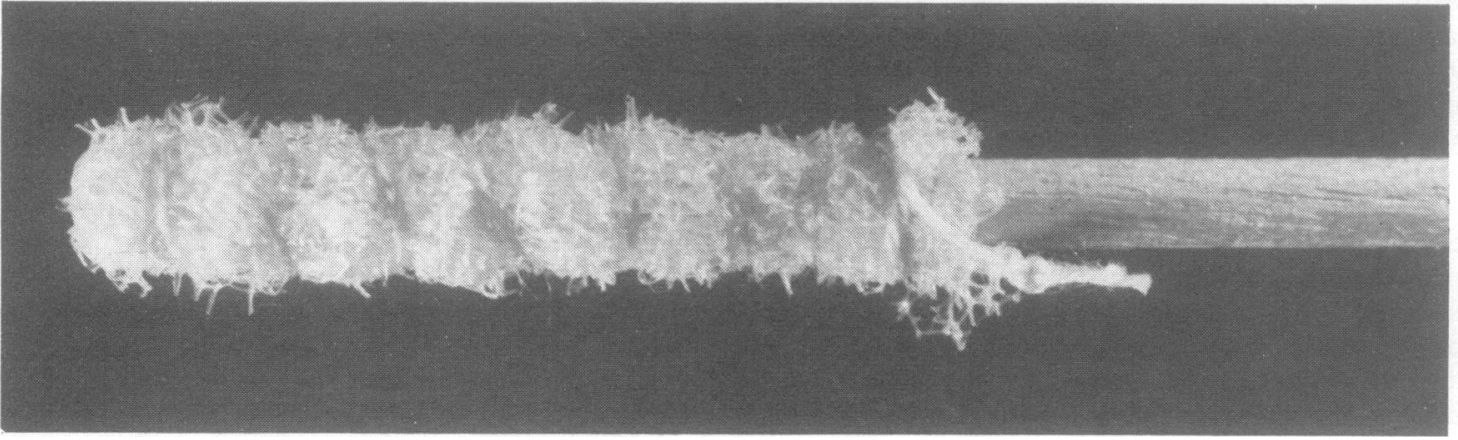

FIGURE $(a)-(d)$ Stages in the production of a polyesterswab by hand; (e) Enlargement of swab head, showing moderately abrasive surface.

urethral specimens the smaller swab was gently inserted into the urethra for about $5 \mathrm{~mm}$. and cautiously rotated one-quarter to a half turn several times. Care was required because the swabs were found to have surprising -albeit useful-abrasive properties and like loops could cause pain and slight bleeding if not used gently. The swabs were then pressed and smeared on clean standard microscopical glass slides, and the tips were broken off into Stuart's transport medium. Inoculation was carried out within $2 \mathrm{hrs}$ on to Nile blue-polymyxin agar (Baker, 1967). If the patient was a known contact of a case of gonorrhoea, two or three slides from both cervix and urethra were prepared with each swab. When the plates were inoculated, the swab with its moderately abrasive surface was rolled gently across a small area of the agar (about $1 \mathrm{sq} . \mathrm{cm}$.) to avoid damaging the medium.

\section{Results and comments LABORATORY TESTS}

The amounts of local secretion taken up by the new swab and by conventional cotton-wool and charcoalimpregnated swabs were determined by accurate weighing before and after use. By testing twelve of 
each type of swab it was found that the sponge swabs absorbed, on average, more than three times as much secretion as the others (Table I). Survival of Neisseria gonorrhoeae was tested in the three types of swab both in air and in Stuart's transport medium kept at approximately $20^{\circ} \mathrm{C}$. The swabs were dipped into a nutrient broth suspension of freshly-isolated gonococci containing $2 \times 10^{3}$ colony-forming organisms per ml., and gonococci were then recoverable as shown in Table II. There was no evident toxic action of the new swab material upon the gonococci. The surprisingly good survival of the organism in the sponge swab was probably due at least partly to the comparatively large volume of broth suspension retained in the inert polyester materal.

\section{TABLE I Uptake of female genital secretions by} swabs

\begin{tabular}{|c|c|c|}
\hline \multirow[b]{2}{*}{$S w a b$} & \multicolumn{2}{|c|}{ Increase in weight (mg.) } \\
\hline & Average & Range \\
\hline Sponge & $107 \cdot 5$ & $40 \cdot 6-172 \cdot 4$ \\
\hline Cotton wool-charcoal & 30.5 & $18 \cdot 6-46 \cdot 8$ \\
\hline Cotton wool alone & $28 \cdot 6$ & $12 \cdot 3-42 \cdot 4$ \\
\hline
\end{tabular}

TABLE II Survival of N. gonorrhoeae on swabs

\begin{tabular}{|c|c|c|}
\hline \multicolumn{2}{|l|}{ Gonococci in } & \multirow{2}{*}{$\begin{array}{l}\text { Loss of viability } \\
\text { in period (hrs) } \\
\begin{array}{r}8-24 \\
52-60\end{array}\end{array}$} \\
\hline Sponge & $\begin{array}{l}\text { Alone } \\
\text { In Stuart's medium }\end{array}$ & \\
\hline Cotton wool & $\begin{array}{l}\text { Alone } \\
\text { In Stuart's medium }\end{array}$ & $\begin{array}{c}2-3 \\
36-52\end{array}$ \\
\hline Charcoal swab & $\begin{array}{l}\text { Alone } \\
\text { In Stuart's medium }\end{array}$ & $\begin{array}{c}5-6 \\
36-52\end{array}$ \\
\hline \multicolumn{2}{|c|}{ Nutrient broth alone } & $8-24$ \\
\hline
\end{tabular}

* Sampled on chocolate agar at hrly intervals for $8 \mathrm{hrs}$, then at 24,36 , 52,60 , and $76 \mathrm{hrs}$

CLINICAL USE

Charcoal-impregnated swabs were used in routine examination in the 12-month period from February 1,1969 , to January 31,1970 . These yielded gonoco-

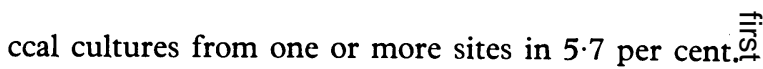
and positive smears from 8.4 per cent. of unselected? cases. In the succeeding 12 -month period the poly-음 ester sponge swabs were used routinely, and gono-s coccal cultures were obtained from 4.8 per cent. of the women, with 9.3 per cent. giving positive smearses (Table III). Thus the number of positive diagnosesobtained with each technique was closely similar.

Although the introduction of the sponge swab in the absence of any further modifications did rot in itself improve our rate of diagnosis of gonorrboea, the collection of adequate specimens was greatly facilitated. In routine use, only one application of $A$ the swab to the cervix or urethra is required andi repeated probing is no longer necessary. The micro- 6 scopical preparations are rapidly made with the 을 swabs, which give a better spreading action than is usual with wire loops and provide a relatively large surface area for subsequent examination. No longer is there any need to clean, prepare, and re-sterilize used loops-a boon in any busy clinic.

Overgrowth of media by $B$. proteus has been an important source of failure to culture gonococcio from specimens with positive smears. Since completing the second series we have routinely added trimethoprim (Seth, 1970) to our Nile blue-poly-o myxin agar and have had no further swarming. We $\frac{\otimes}{8}$ now also inoculate and incubate media in the clinic $\stackrel{\varrho}{\Rightarrow}$ without delay. This, too, should give improved culture results.

The sponge swab in the diagnosis of Trichomonas and Candida infections and in cytology

A swab is dipped into the vaginal pool of secretion and then gently rubbed on any area of the vaginal $\delta$ wall which appears to be inflamed. It is then used to make a smear which is Gram-stained and examined 0 for the presence of fungal elements. The swab is next rubbed and pressed into a drop of Trichomonas vaginalis medium (R27, Oxoid) on a slide, and is finally placed in a bijou bottle of the same medium? for culture. The wet film is examined for the presence $N$ of fungal elements and motile trichomonads. Our impression is that this method is as reliable as any

TABLE III Gonococci in smears and cultures from unselected female patients

\begin{tabular}{|c|c|c|c|c|c|c|c|}
\hline \multirow{3}{*}{ Specimens } & \multirow{3}{*}{$\begin{array}{l}\text { No. of } \\
\text { patients }\end{array}$} & \multicolumn{4}{|c|}{ Gonococci from: } & \multicolumn{2}{|c|}{$\begin{array}{l}\text { No. and percentage of patients } \\
\text { with positive: }\end{array}$} \\
\hline & & \multicolumn{2}{|c|}{ Urethra } & \multicolumn{2}{|l|}{ Cervix } & \multirow[b]{2}{*}{ Smear } & \multirow[b]{2}{*}{ Culture } \\
\hline & & Smear & Culture & Smear & Culture & & \\
\hline $\begin{array}{l}\text { Loop and charcoal swab } \\
\text { Sponge swab }\end{array}$ & $\begin{array}{l}1,118 \\
1,082\end{array}$ & $\begin{array}{l}52 \\
52\end{array}$ & $\begin{array}{l}54 \\
38\end{array}$ & $\begin{array}{l}78 \\
61\end{array}$ & $\begin{array}{l}52 \\
46\end{array}$ & $\begin{array}{r}94(8 \cdot 4) \\
101(9 \cdot 3)\end{array}$ & $\begin{array}{l}64(5 \cdot 7) \\
52(4 \cdot 8)\end{array}$ \\
\hline
\end{tabular}


previously employed, and there can be no doubt of its speed and efficiency in the collection of samples.

By virtue of its abrasive properties the foam swab is also uniquely suitable for preparing slides for cervical cytology tests; rubbing the swab across the cervix, or gently rotating it inside the cervical canal, always produces adequate specimens. Foam swabs for such a purpose have been suggested before (Watson, 1966), but the polyvinyl sponge used becomes too hard and dry in air for our purposes.

\section{CONCLUSIONS}

The polyester foam swab is considered to have the following advantages when used to collect specimens from female patients undergoing examination to detect the presence of infections of the lower genital tract.

(1) Ample specimens are rapidly obtained with fewer manoeuvres during examination and with less discomfort for the patient. One swab provides for three or more slides from each site tested and gives ample material for gonococcal culture. Gonococci survive well in the swab.

(2) The swabs are very satisfactory for the detection of Trichomonas vaginalis and Candida albicans by both smear and culture techniques.

(3) The swabs provide excellent specimens for exfoliative cytology because of their moderately abrasive surface. The swabs are, in our opinion, more efficient than the conventional Ayre's type of spatula. (4) The swabs avoid the need for platinum loops which are troublesome in sterilization and maintenance.

The swabs would constitute an economical and standardized prepack for the performance of genital tests on women. The user must only remember to select the smaller swab when taking urethral specimens and to use care when inoculating soft agar plates.

Supplies of this form of swab will soon be commercially available .

\section{Summary}

A small polyester sponge swab has been designed and tested in the examination of women for genital infections. It absorbs over three times as much genital secretion as conventional swabs, facilitates the rapid collection of specimens for microscopy and ^From Bradgate-Unitech Ltd., Gateway House, Gateway Street, Leicester LE2 7DP culture in the diagnosis of gonococcal, trichomonal, and candida infections, and is also very suitable for obtaining specimens for cervical cytology because of its moderately abrasive texture. In laboratory tests gonococci survived more than $8 \mathrm{hrs}$ in the swab without the use of transport medium. In routine clinic use, gonococcal cultures were obtained from the sponge swabs in about 5 per cent. of 1,082 unselected women attending the clinic. Equivalent numbers of positive cultures were obtained in a series of 1,118 women examined by the more laborious use of wire loops and charcoal-coated swabs. Positive smears were obtained in about 9 per cent. of cases in both series.

Our thanks are due to Sister C. Denehan, O.P.6, Westminster Hospital who prepared the swabs used in this investigation.

\section{References}

BAKER, F. J. (1967) 'Handbook of Bacteriological Technique', 2nd ed. Butterworths, London

Catterall, R. D. (1970) Brit. F. vener. Dis., 46, 122

NORINS, L. C. (1968) Ibid., 44, 103

SETH, A. (1970) Ibid., 46, 201

ThIN, R. N. T. (1970) Ibid., 46, 27

Watson, A. A. (1966) Lancet, 1, 957

\section{Utilisation d'une éponge en polyester pour faciliter} l'examenen cas d'infection génitale féminine

\section{SOMMAIRE}

Un petit écouvillon en éponge de polyester a été imaginé et étudié pour l'examen de femmes présentant des infections génitales, Celui-ci absorbe plus de trois fois plus de sécrétions génitales que les écouvillons classiques, il facilite le recueil rapide d'échantillons pour les lames et la culture, dans le diagnostic des infections à gonocoques, à Trichomonas ou à Candida et il est aussi très approprié pour la cytologie cervicale car il est composé d'une matière un peu abrasive. Pour les examens au laboratoire, les gonocoques ont survécu plus de $\mathbf{8}$ heures sur l'écouvillon sans qu'il faille utiliser un milieu de transport. En utilisation clinique de routine, des cultures de gonocoques furent obtenues à partir de cet écouvillon dans environ 5 pour cent de 1.082 femmes, non choisies, consultant à la clinique. Un nombre équivalent de cultures positives fut obtenu dans une série de 1.118 femmes examinées en employant, d'une manière moins facile, le fil à prélèvements ou l'écouvillon de coton charboné. Les lames furent positives dans environ 9 pour cent des cas dans les deux séries. 